\title{
PATOLOGIAS EM PAVIMENTOS ASFÁLTICOS - UM ESTUDO DE CASO DA AVENIDA VICENTE NUNES DE ALBUQUERQUE
}

\author{
ARAUJO, JANCLÉIA ALBUQUERQUE \\ Graduanda em Engenharia Civil \\ IFAL- Campus Palmeira dos Índios \\ Alagoas; Brasil \\ jancleialbuquerq@gmail.com
}

\author{
BARBOSA, LUANA FELIX \\ Graduanda em Engenharia Civil \\ IFAL- Campus Palmeira dos Índios \\ Alagoas; Brasil \\ luanafelix1@hotmail.com
}

\author{
PINTO, ISABELLY CHRISTINY MONTEIRO DE SOUZA PINTO \\ Docente \\ IFAL- Campus Palmeira dos Índios \\ Alagoas; Brasil \\ isabellycmsp@gmail.com
}

\begin{abstract}
RESUMO
O pavimento asfáltico representa quase toda a malha rodoviária pavimentada no Brasil e sendo assim, o estudo de suas patologias é importante para assegurar a conservação e garantir que atenda a segurança e o conforto na trafegabilidade dos veículos. Neste sentido, este trabalho propõe-se caracterizar as patologias que interferem na qualidade do pavimento asfáltico na Avenida Vicente Nunes de Albuquerque, localizada na cidade de Arapiraca-AL. Para isso, fez-se um levantamento de dados através de análise visual, percorrendo toda a extensão da via, nos dois sentidos de tráfego. Com o acervo fotográfico criado foi possível verificar que se destacaram alguns tipos de patologias, sendo elas: panelas, afundamentos, remendos, problemas de drenagem, de execução e de manutenção. comprometem a segurança e a qualidade do deslocamento. Como essas patologias estão presentes em todos os trechos analisados, verificou-se que seria ideal refazer a base e o revestimento asfáltico para solucionar também a degradação das camadas inferiores, uma vez que apenas uma ação tapa-buracos poderia trazer grande desconforto. Contudo, conhecer as causas de seus defeitos se mostrou importante para possibilitar que se encontre a melhor forma de recuperação, visando garantir o conforto e a segurança dos usuários.
\end{abstract}

Palavras-chave: patologia, pavimento asfáltico, recuperação.

\section{ABSTRACT}

The asphalt pavement represents almost the entire paved road network in Brazil and, therefore, the study of its pathologies is important to ensure conservation and ensure that it meets safety and comfort in the traffic of vehicles. In this sense, this work aims to characterize the pathologies that interfere with the quality of the asphalt pavement on Avenida Vicente Nunes de Albuquerque, located in the city of Arapiraca-AL. For this, a data survey was made through visual analysis, covering the entire length of the road, in both directions of traffic. With the created photographic collection, it was possible to verify that some types of pathologies stood out, namely: pots, sinks, patches, drainage, execution and maintenance problems. compromise the safety and quality of travel. As these pathologies are present in all the analyzed stretches, it was found that it would be ideal to redo the base and the asphalt coating to also solve the degradation of the lower layers, since only a stop-gap action could bring great discomfort. However, knowing the causes of your defects proved to be important to enable you to find the best form of recovery, aiming to ensure the comfort and safety of users.

Keywords: pathology, asphalt pavement, recovery. 


\section{INTRODUÇÃO}

Atualmente, no Brasil, a malha rodoviária é o principal meio de transporte de mercadorias e deslocamento de pessoas, sendo responsável por aproximadamente $90 \%$ do transporte de passageiros e mais de $60 \%$ no transporte de cargas que circulam no País. Da malha atual de 1.720 .756 km, somente 211.468 km são pavimentados, e mais de $99 \%$ da malha rodoviária pavimentada é de pavimento flexível (CNT, 2017).

No final do século XIX, constatou-se uma evolução no uso das vias pelos veículos tracionados mecanicamente. Isso foi acompanhado de diversas deficiências da utilização pura e simples de camadas granulares em pavimentos, como propunham franceses e ingleses cem anos antes (BALBO, 2007).

Nesse sentido, é importante destacar que a mudança do comportamento de um pavimento é bastante complexa, pois cada ação ocasiona uma alteração específica sobre as características dos materiais constituintes das camadas dos pavimentos.

O fato pode ser constatado através de uma avaliação funcional. A mesma consiste na determinação através da identificação e quantificação da ocorrência de defeitos superficiais, que busca determinar o grau de deterioração da rodovia, principalmente nos aspectos que afetam a segurança e o conforto dos usuários (ECHEVERRIA, 2011).

O aparecimento de degradações num pavimento, por sua vez, é um sinal indicativo de que a capacidade estrutural ou funcional para que foi projetado é insuficiente para suportar as ações do tráfego e das condições climáticas (FRANCISCO, 2012).

Segundo EIRAS et al. (2018), para o pavimento flexível, aparecem degradações devido ao desgaste pelo tempo de uso da via e cargas excessivas aplicadas sobre ele. Essas degradações podem ser encontradas na forma de fendas, afundamentos, corrugação ou ondulações transversais, exsudação, desgaste ou desagregação, panela ou buraco e remendos, de acordo com a norma DNIT 005/2003-TER.

Portanto, a avaliação da qualidade dos pavimentos consiste num conjunto de atividades que permitem conhecer o estado do pavimento num determinado instante, baseia-se na definição de critérios objetivos quanto à análise da interação entre o estado do pavimento, a respetiva capacidade estrutural e o utente da estrada.

BERNUCCI et al. (2008) relatam que os levantamentos dos defeitos de superfície são importantes para a avaliação da conservação dos pavimentos asfálticos e embasa o diagnóstico da situação funcional para que, havendo necessidade, seja possível indicar a melhor ou as melhores alternativas de restauração.

Com base na bibliografia, o presente artigo buscou estudar as patologias mais frequentes em pavimentos asfálticos. Uma análise visual foi feita posteriormente em toda a extensão de uma via coletora localizada na cidade Arapiraca-AL a fim de comparação do caso real com as informações obtidas pela literatura.

\section{REFERENCIAL TEÓRICO}

\subsection{Pavimento: considerações gerais}

O pavimento pode ser definido como “... uma estrutura de múltiplas camadas de espessuras finitas, construída sobre a superfície final de terraplenagem, destinada técnica e economicamente a resistir aos esforços oriundos do tráfego de veículos e do clima, e a propiciar aos usuários melhoria nas condições de rolamento, com conforto, economia e segurança" (BERNUCCI et al., 2008).

As camadas do pavimento são identificadas como: subleito, sub-base, base e revestimento. De acordo com ROSSI (2017), o subleito recebe toda a estrutura do pavimento e funciona como a fundação do sistema que irá receber os esforços absorvidos pelo pavimento. Acima do subleito encontra-se uma regularização do subleito, um reforço de subleito, caso haja necessidade, uma sub-base acima desse reforço, seguido de uma base e por fim de um revestimento.

GUSMÃO (2009), afirma que o subleito é constituído de material de origem natural, consolidado, compactado ou composto por material transportado e compactado, sendo sua regularização uma camada de espessura irregular construída sobre ele com o intuito de conformá-lo, transversal e longitudinalmente com o projeto. Para SENÇO (2017), a sub-base é considerada a camada complementar à base e não existe necessidade de construir a base diretamente sobre a camada de regularização ou reforço do subleito. 
Conforme MARQUES (2014), base é a camada que tem como função aliviar a tensão nas camadas inferiores, permitir a drenagem das águas que se infiltram no pavimento e resistir às tensões e deformações atuantes. E o revestimento é a camada que recebe a ação do rolamento dos veículos, destinada a melhorar as condições de rolamento quanto à comodidade e segurança, e resistir aos esforços que nele atuam, tornando a superfície de rolamento mais durável.

Segundo BALBO (2007), cada camada do pavimento possui uma ou mais funções específicas e devem proporcionar aos veículos condições adequadas de rolamento e suporte em qualquer ação climática.

Quanto à classificação, os pavimentos podem ser: rígidos e flexíveis. O primeiro apresenta uma camada de revestimento com uma rigidez superior às camadas inferiores, absorvendo praticamente todas as tensões provenientes das tensões e deformações da placa. Seu modelo é baseado na implementação de cimento como aglomerante hidráulico para interligação dos agregados envolvidos no concreto e a placa de cimento seu principal componente estrutural (ARAÚJO et al., 2014).

Já o segundo é caracterizado por não romper e é constituído principalmente de materiais betuminosos. Sua base pode ser composta por diversas camadas, como subleito, sub-base, base e revestimento. Seus esforços são distribuídos verticalmente (ARAÚJO et al., 2014).

\subsection{Revestimentos Asfálticos}

O revestimento asfáltico é a camada superior destinada a resistir diretamente às ações do tráfego e transmiti-las às camadas inferiores, impermeabilizar o pavimento e melhorar as condições de rolamento como o conforto e a segurança. São constituídos por associação de agregados e de materiais asfálticos, podendo ser por penetração ou por mistura. Por penetração refere-se aos executados através de uma ou mais aplicações de material asfáltico e de idêntico número de operações de espalhamento e compressão de camadas de agregados com granulometrias apropriadas. Por mistura, o agregado é pré-envolvido com o material asfáltico, antes da compressão (BERNUCCI et al., 2008).

De acordo com MARQUES (2014), na camada de revestimento pode-se usar o Concreto de Cimento Porland (CCP) ou Concreto Betuminoso Usinado a Quente (CBUQ) ou Stone Matrix Asphalt (SMA), para o tráfego pesado, e o PMQ (Pré-Misturado a Quente), para tráfego leve. Pode-se usar em alguns casos o PMF (Pré-Misturado a Frio) e o TSD (Tratamento Superficial Duplo) por penetração invertida.

O concreto betuminoso usinado a quente (CBUQ) é um dos mais empregados no Brasil. Trata-se da mistura convenientemente proporcionada de agregados de vários tamanhos e cimento asfáltico, ambos aquecidos em temperaturas previamente escolhidas, em função da característica viscosidade-temperatura do ligante (BERNUCCI $e t$ al., 2008).

Segundo COELHO JR \& ROCHA (2013), as misturas asfálticas a quente podem ser subdivididas pela graduação dos agregados e fíler e os mais usuais nas misturas a quente são: graduação densa, constituída de uma curva granulométrica contínua e bem-graduada de forma a proporcionar um esqueleto mineral com poucos vazios; graduação aberta, formada por uma curva granulométrica uniforme com agregados quase exclusivamente de um mesmo tamanho, de forma a proporcionar um esqueleto mineral com muitos vazios, possibilitando a percolação de água no interior da mistura asfáltica; e graduação descontínua, composta por uma curva granulométrica com proporcionalmente dos grãos de maiores dimensões em quantidade dominante em relação aos grãos de dimensões intermediárias, completados por certa quantidade de finos, de forma a ter uma curva descontínua em certas peneiras, com o objetivo de tornar o esqueleto mineral mais resistente à deformação permanente.

\subsection{Defeitos de Superfície}

\subsubsection{Trinca}

De acordo com a norma DNIT 005/2003 - TER, trinca pode ser definida como fenda existente no revestimento, facilmente visível, com abertura superior à da fissura, podendo se apresentar sob a forma de trinca isolada ou interligada. 


\section{$\checkmark$ Trinca isolada}

A norma DNIT 005/2003 - TER classifica a trinca isolada em três tipos:

- Trinca transversal: que apresenta direção predominantemente ortogonal ao eixo da via. Quando apresentar extensão de até $100 \mathrm{~cm}$ é denominada trinca transversal curta. Quando a extensão for superior a $100 \mathrm{~cm}$ denomina-se trinca transversal longa.

- Trinca longitudinal: apresenta direção predominantemente paralela ao eixo da via. Quando apresentar extensão de até $100 \mathrm{~cm}$ é denominada trinca longitudinal curta. Quando a extensão for superior a $100 \mathrm{~cm}$ denomina-se trinca longitudinal longa.

- Trinca de retração: não atribuída aos fenômenos de retração térmica ou do material do revestimento ou do material de base rígida ou semi-rígida subjacentes ao revestimento trincado.

\section{$\checkmark$ Trincas interligadas}

As trincas interligadas são subdivididas em: trincas de bloco (TB) quando tendem a uma regularidade geométrica, ou ainda (TBE) quando as trincas de bloco apresentam erosão junto às suas bordas; trincas tipo couro de jacaré (J) quando não seguem um padrão de reflexão geométrico de trincas como as de bloco e são comumente derivadas da fadiga do revestimento asfáltico, ou ainda (JE) quando as trincas tipo couro de jacaré apresentam erosão junto às suas bordas (BERNUCCI et al., 2008).

\subsubsection{Afundamento}

Consiste na deformação permanente caracterizada por depressão da superfície do pavimento, podendo ser acompanhada de solevamento e podendo apresentar-se sob a forma de afundamento plástico ou de consolidação (DNIT 005/2003 TER).

\section{$\checkmark$ Afundamento plástico}

Afundamento causado pela fluência plástica de uma ou mais camadas do pavimento ou do subleito, acompanhado de solevamento. Quando ocorre em extensão de até $6 \mathrm{~m}$ é denominado afundamento plástico local; quando a extensão for superior a $6 \mathrm{~m}$ e estiver localizado ao longo da trilha de roda é denominado afundamento plástico da trilha de roda.

\section{$\checkmark$ Afundamento de consolidação}

Afundamento de consolidação é causado pela consolidação diferencial de uma ou mais camadas do pavimento ou subleito sem estar acompanhado de solevamento. Quando ocorre em extensão de até $6 \mathrm{~m}$ é denominado afundamento de consolidação local; quando a extensão for superior a $6 \mathrm{~m}$ e estiver localizado ao longo da trilha de roda é denominado afundamento de consolidação da trilha de roda.

\subsubsection{Ondulação/ Corrugação}

Segundo BERNUCCI et al. (2008) corrugações são deformações transversais ao eixo da pista, com depressões intercaladas de elevações e com comprimento de onda entre duas cristas de alguns centímetros ou dezenas de centímetros.

\subsubsection{Panela}

Cavidade que se forma no revestimento por diversas causas, inclusive por falta de aderência entre camadas superpostas que causam o desplacamento das camadas. Podem alcançar as camadas inferiores do pavimento, provocando a desagregação das camadas (DNIT 005/2003 - TER).

\subsubsection{Remendo}

Apesar de estar relacionado a uma conservação da superfície, o remendo é um tipo de defeito que se caracteriza pelo preenchimento de panelas ou de qualquer outro orifício ou depressão com massa asfáltica (BERNUCCI et al., 2008). 


\section{METODOLOGIA}

Realizou-se um estudo de caso na Avenida Vicente Nunes de Albuquerque localizada no bairro de Caititus, na cidade de Arapiraca-AL. A mesma possibilita acessibilidade a importantes polos geradores de viagens (PGV'S).

O levantamento de dados foi realizado através de análise visual, percorrendo toda a sua extensão, nos dois sentidos de tráfego. Os defeitos encontrados foram anotados e fotografados para a posterior análise.

Os dados e o acervo fotográfico de vários pontos da avenida foram utilizados para identificar as patologias mais frequentes no pavimento asfáltico analisado. Após a identificação, a revisão bibliográfica foi feita a fim de determinar as principais causas dessas patologias e suas possíveis recuperações. Na Figura 1 é possível visualizar a avenida considerada na pesquisa de campo.

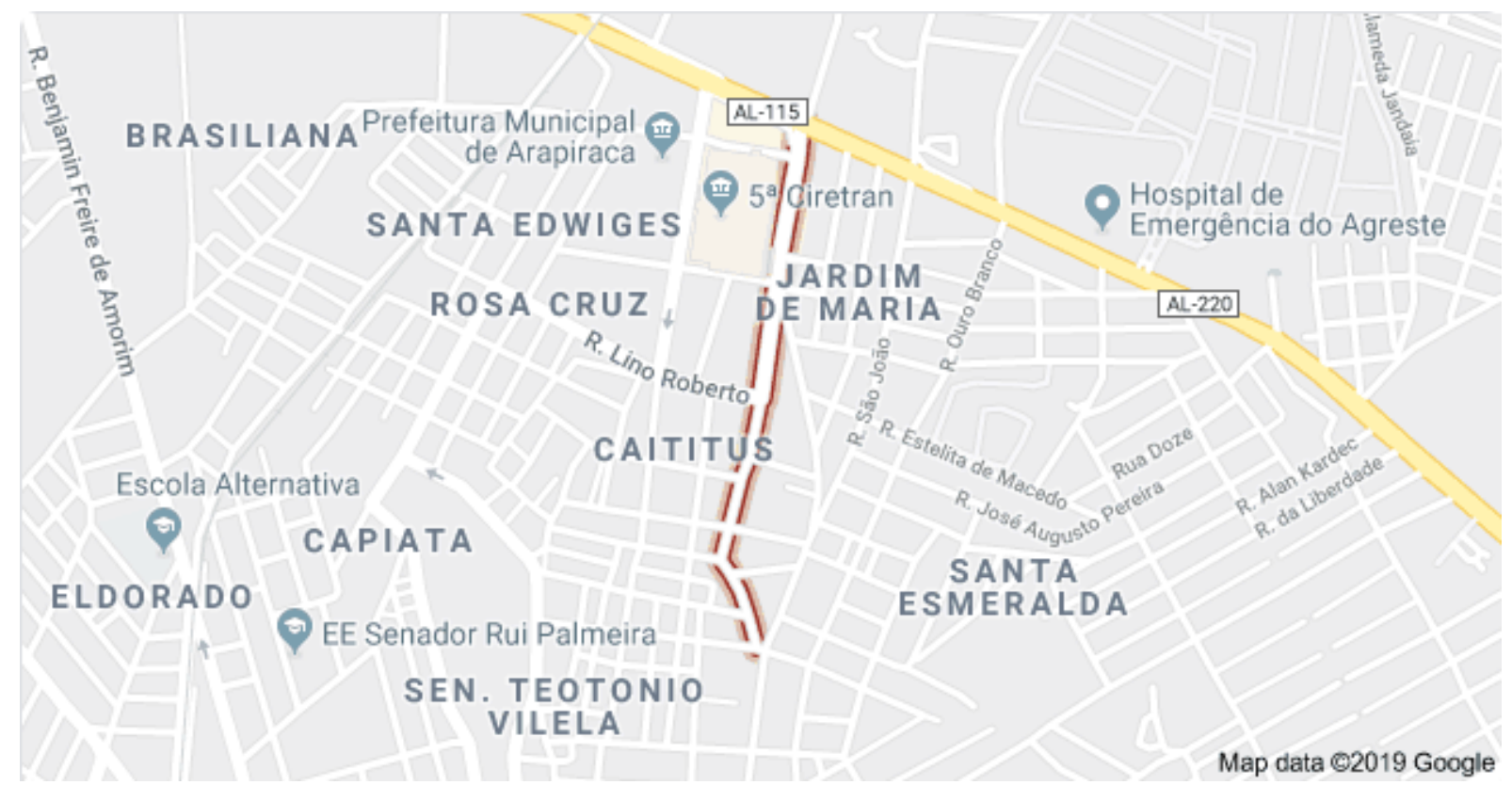

Figura 1: Avenida considerada na pesquisa de campo

\section{RESULTADOS}

No estudo de caso realizado na Avenida Vicente Nunes de Albuquerque, cidade de Arapiraca-AL, foram analisadas as camadas mais superficiais do pavimento, visto que é nelas que ficam aparentes as irregularidades e a perda de qualidade.

Através do acervo fotográfico criado a partir de vários pontos do revestimento asfáltico foi possível notar que se destacaram alguns tipos de patologias, sendo elas: panelas, afundamentos, remendos, problemas de drenagem, de execução e de manutenção.

\subsection{Panelas}

Notou-se ao longo do trecho percorrido a ocorrência de panelas de magnitudes variadas. A existência dessas panelas compromete a segurança do tráfego, pois os motoristas costumam tentam desviar, podendo causar acidentes no percurso. Na Figura 2 é possível identificar a presença desta patologia.

De acordo com o Manual de restauração de pavimentos asfáltico (DNIT, 2006), as causas desse defeito podem estar relacionadas ao trincamento por fadiga e pela desintegração localizada na superfície do pavimento. Podem ocorrer em qualquer área, principalmente nas trilhas de roda e seu início e evolução são aceleradas pela ação do tráfego e por fatores climáticos. 


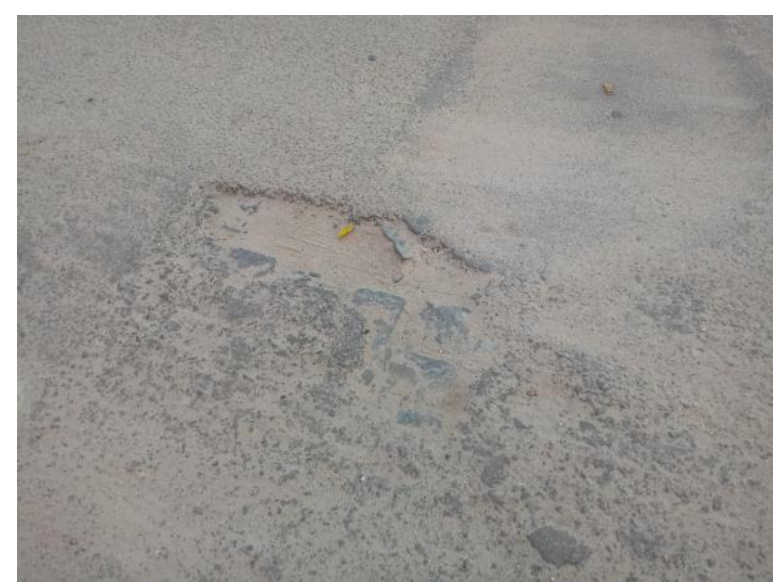

Figura 2: Panela localizada na Avenida estudada.

\subsection{Afundamentos}

Ao longo de alguns trechos haviam afundamentos de revestimento, caracterizados por depressão na região das trilhas de rodas. Segundo Marque (2014), esses afundamentos possibilitam infiltração e acúmulo de água proveniente da chuva, além de exigirem ações mais radicais e maior custo para recuperação. Na Figura 3 verificou a existência de um afundamento localizado.

Por ser caracterizado como afundamento localizado, é causado pela fluência plástica de uma ou mais camadas do pavimento ou do subleito, conforme a norma DNIT 005/2003 - TER.

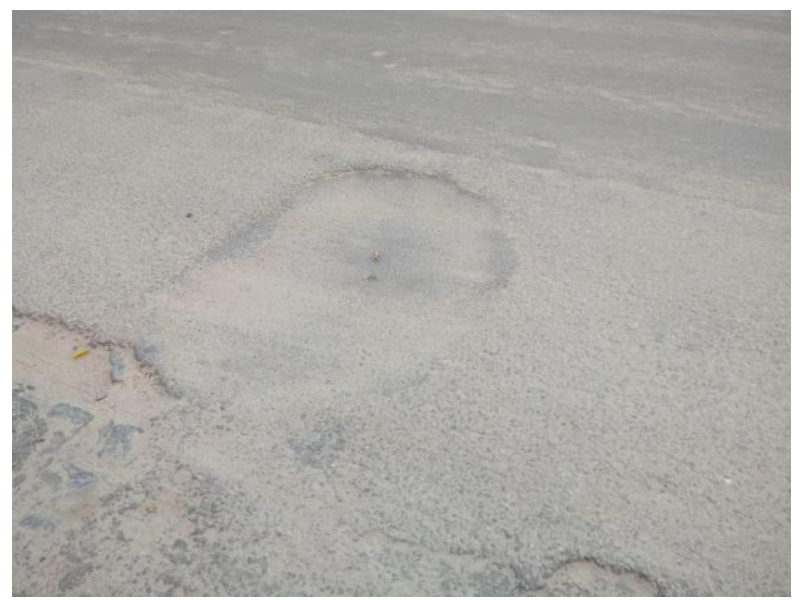

Figura 3: Afundamento localizado na Avenida estudada.

\subsection{Remendos}

Foi observado, na figura 4, a existência de remendos que apresentam deterioração ao longo do trecho estudado. Apesar de ser uma atividade de conservação, remendos são considerados como defeitos por apontarem um local de fragilidade do revestimento e por provocar danos ao rolamento (MARQUES, 2014).

Segundo o Manual de restauração de pavimentos asfáltico (DNIT, 2006), os remendos são considerados defeitos quando provocam desconforto e as causas para isso seriam: solicitação intensa do tráfego, emprego de material de má qualidade, agressividade das condições ambientais e problemas construtivos. 


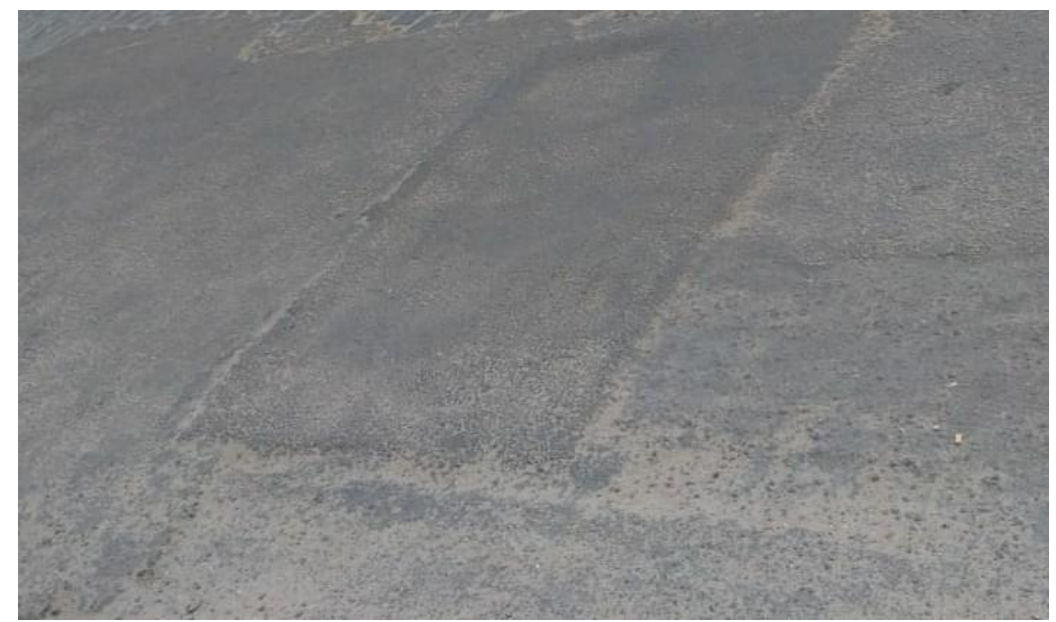

Figura 4: Remendo localizado na Avenida estudada.

\subsection{Problemas de drenagem}

Problemas devido à falta de drenagem superficial, também são comuns na Avenida em questão, como mostrado na Figura 5, colaborando com a deterioração do pavimento. Com uma drenagem deficiente, a presença da água no asfalto evolui e gera a fragmentação e até a remoção de partes do revestimento e/ou da base (CAVALCANTE, 2012).

De acordo com o Manual de restauração de pavimentos asfáltico (DNIT, 2006), problemas de drenagem como os detectados na Avenida Vicente Nunes de Albuquerque necessitam da adoção de medidas para a proteção do corpo estradal da ação prejudicial das águas que o atingem, seja por meio das precipitações, das infiltrações, da condução através de talvegues, ou mesmo, das existentes sob a forma de lençóis freáticos ou artesianos.

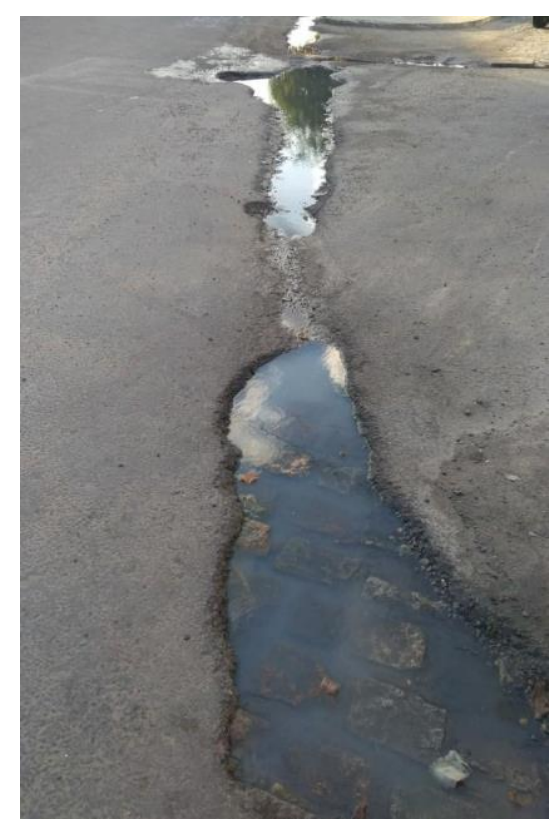

Figura 5: Problemas de drenagem na Avenida estudada.

\subsection{Problemas de execução e de manutenção}

$\mathrm{Na}$ Avenida analisada, o asfalto foi aplicado sobre o paralelepípedo existente. Em vários trechos foi possível observar o desprendimento do asfalto, conforme visto na Figura 6.

Com o aumento do tráfego na via há aumento da carga sobre o pavimento e pela falta de compactação abaixo dos paralelepípedos podem ser comuns afundamentos e desníveis. Um outro problema que surge ao se colocar asfalto sobre 
o paralelepípedo é a falta de imprimação para que haja aderência entre os mesmos e é questão de tempo para o asfalto se desprender. (GEWEHR, 2013).

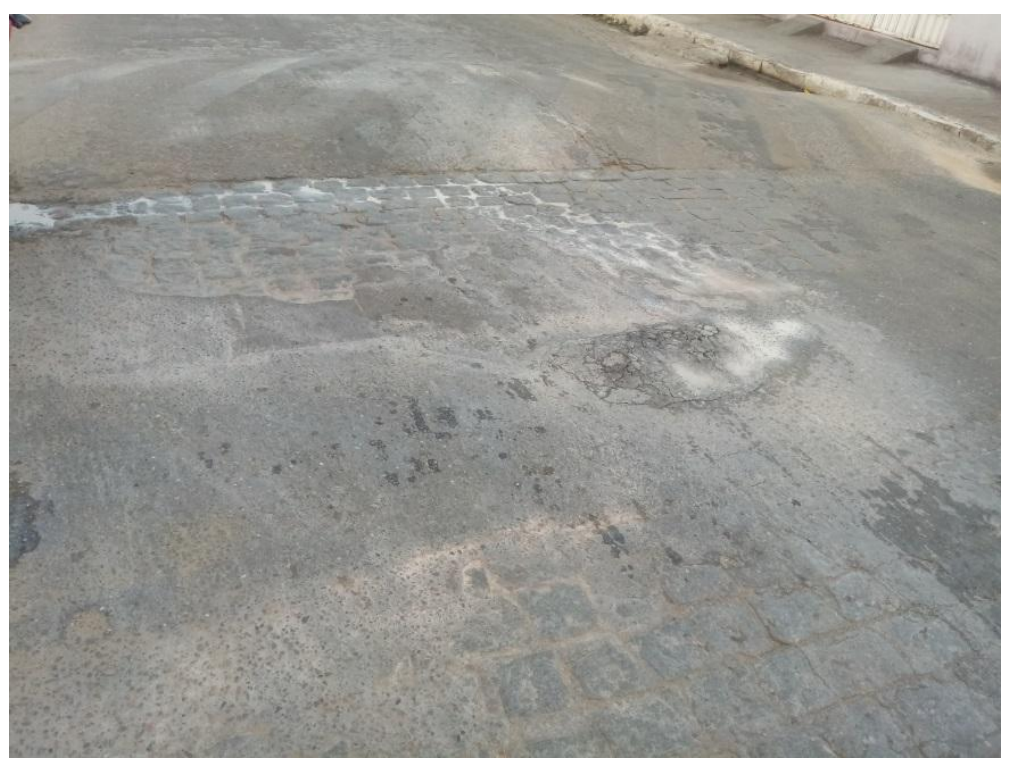

\section{CONCLUSÃO}

Figura 6: Asfalto se desprendendo na Avenida estudada.

Considerando o objetivo deste trabalho, que consistiu em identificar as patologias mais frequentes em pavimentos asfálticos, pode-se concluir que os defeitos apresentados na Avenida Vicente Nunes de Albuquerque prejudicam o conforto e a segurança dos motoristas que utilizam a rodovia, e foram causados pela falta de manutenção e a inexistente recuperação do pavimento.

Por se tratar de uma avenida de grande importância, já que ela passa por polos geradores de viagens como Arapiraca Garden Shopping, o ideal seria refazer a base e o revestimento asfáltico para solucionar também a degradação das camadas inferiores e a criação de um projeto de restauração pelo órgão responsável, já que as medidas de manutenção realizada não solucionaram os problemas totalmente.

Contudo, é necessário analisar as causas dos defeitos, para então ser realizada uma análise técnico-econômica e assim escolher as medidas mais adequadas para a revitalização.

\section{REFERÊNCIAS}

ARAúJO, M. A.; SANTOS, M. J. P.; PINHEIRO, H. P.; CRUZ, Z. V. Análise Comparativa de Métodos de Pavimentação - Pavimento Rígido (concreto) x Flexível (asfalto). Revista Científica Multidisciplinar Núcleo Do Conhecimento. Ano 01, Edição 11, Vol. 10, pp. 187-196, 2016.

BALBO, J. Projeto e restauração. Oficina de Textos. São Paulo, 2007.

BernuCCI, L. B.; MOTTA, L. M. G.; CERATTI, J. A. P.; SOARES, J. B. (2008). Pavimentação asfáltica formação básica para engenheiros. Rio de Janeiro, RJ: Petrobras/Abeda, 504p, 2008.

BRASIL. Departamento Nacional de Infraestrutura de Transporte. DNIT IPR/720: Manual de restauração de pavimentos asfálticos. Rio de Janeiro, 2006.

BRASIL. Departamento Nacional de Infraestrutura de Transporte. DNIT 005/2003 - TER: Defeitos nos pavimentos flexíveis e semirrígidos - Terminologia. 2003. 12p. Rio de Janeiro, 2003.

CAVAlCANTE, D. G; CRISÓSTOMO, P. H. S; SILVA, L. C. P; SOUZA, R. J. Q; GUIMARÃES, D. M. D; FROTA, C. A. Levantamento Visual das Patologias na Cidade de Manaus-AM. Revista Teoria e Prática na Engenharia Civil. N.19. p.77-87, 2012. 
COELHO JR., M.L.P.; ROCHA, P.H.T. Estudo preliminar de misturas asfálticas à quente utilizadas em obras de pavimentação na região metropolitana de Goiânia. Trabalho de Conclusão de Curso, Universidade Federal de Goiás. Goiânia, Goiás, 2013.

CONFEDERAÇÃO NACIONAL DO TRANSPORTE. Transporte rodoviário: por que os pavimentos das rodovias do Brasil não duram? 2017. 160p. Brasília: CNT, 2017.

ECHEVERRIA, J. A. S. Avaliação do efeito de restaurações com fresagem e recapeamento nas condições funcional e estrutural de pavimentos com volume de tráfego médio. Dissertação (mestrado) - Universidade Federal do Rio Grande do Sul. Porto Alegre, 2011.

EIRAS, D. H. M.; PEREIRA, L. T; PAIVA, P. N. C.; GOMES, G. J. C. A importância da composição da massa asfáltica para um bom desempenho. Revista Teccen. 2018; 11 (2): 65-72.

FRANCISCO, A. P. S. Comportamento Estrutural de Pavimentos Rodoviários Flexíveis. Dissertação (Mestrado em Engenharia da Construção) - Escola Superior de Tecnologia e de Gestão Instituto Politécnico de Bragança. Bragança, 2012.

GEWEHR, J. Asfalto sobre paralelepípedos: um erro. Disponível em: <http://asfaltodequalidade.blogspot.com/2013/10/asfalto-sobre-paralelepipedos-um-erro.html>. Acesso em: 15 de Agosto de 2019.

GUSMÃO, M. Restauração rodoviária usando asfalto modificado por polímero. Dissertação (Mestrado) Universidade Federal de Ouro Preto. Ouro Preto, 2009.

MARQueS, G. B. Análise de Pavimento Flexível: Estudo de um Trecho Crítico na Rodovia ERS-421. Trabalho de Conclusão de Curso (Bacharelado em Engenharia Civil) - Centro Universitário UNIVATES. Lajeado, 2014.

ROSSI, A. C. Etapas de uma obra de pavimentação e dimensionamento para uma via na Ilha do Fundão. Projeto de Graduação - UFRJ / Escola Politécnica / Curso de Engenharia Civil. Rio de Janeiro, 2017.

SENÇO, W. Manual de Técnicas de Pavimentação. Volume 2, Ed. Pini. São Paulo, 2001. 